YАK $616.34,616-005.4$

DOI: 10.24884/1682-6655-2021-20-2-70-76

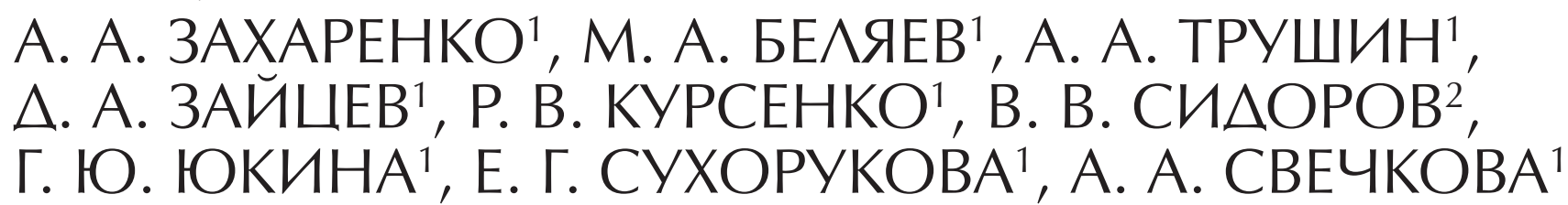

Комбинированная ощенка жизнеспособности кишки методами лазерной Аопплеровской флоуметрии и мазерной фмуоресцентной спектроскопии

1 Федеральное государственное бюджетное образовательное учреждение высшего образования

«Первый Санкт-Петербургский государственный медицинский университет имени акахемика И. П. ПавАова»

Министерства зАравоохранения Российской Фехеращии, Санкт-Петербург, Россия

197022, Россия, Санкт-Петербург, ум. Аьва Толстого, А. 6-8

${ }^{2}$ Обшество с ограниченной ответственностью «Научно-производственное предприятие "ААЗМА"», Москва, Россия

123458, Россия, Москва, ул. Твардовского, А. 8

E-mail: 9516183@mail.ru

\title{
Резюме
}

Введение. Разработка объективного неинвазивного способа интраоперационной оценки жизнеспособности кишки остается актуальной проблемой современной хирургии. В данном контексте малоизученным и перспективным представляется способ лазерной флуоресцентной спектроскопии (ЛФС) коферментов окислительного метаболизма, а также комбинация указанной методики с одновременным использованием лазерной допплеровской флоуметрии (ЛДФ). Материальl и методbl. На модели ишемии-реперфузии тонкой кишки 4 животных породы «Кролик Калифорнийский» исследована взаимосвязь параметров ЛФС и ЛДФ с гистологической картиной. Использована модель интраоперационной ишемии путем временного пережатия ствола краниального брыжеечного сосудистого пучка на 90 мин с последующей интраоперационной и послеоперационной реперфузией в течение 60 мин и 24 ч, соответтсвенно. Регистрация параметров ЛФС и ЛДФ со стенки исследуемого участка кишки проводилась в конце интраоперационного реперфузионного периода. Через 24 часа послеоперационного периода проведена гистологическая оценка обратимости ишемических изменений в тонкой кишке и их сопоставление с параметрами ЛФС и ЛДФ. Проанализирована диагностическая ценность ЛФС, ЛДФ, а также их комбинации при оценке жизнеспособности кишки. Результаты. Получена значимая корреляция между параметрами ЛДФ, ЛФС и степенью ишемических изменений по данным гистологического исследования. Наибольшей диагностической ценностью обладает способ изолированной оценки разницы флуоресценции восстановленного никотинадениндинуклеотида (НАДН) до и после ишемии-реперфузии $(77,3$ \%). Наибольшая чувствительность метода получена при комбинации разниц значений ЛДФ и ЛФС до и после ишемии-реперфузии $(85,7$ \%) $(\mathrm{P}<0,05)$. Bblвoдbl. ЛФС, а также комбинация ее с ЛДФ является полезным методом для объективной оценки жизнеспособности кишки, требующим дальнейших исследований и имеющим потенциал для клинического использования.

Ключевые слова: микрочиркуляция, несостоятельность анастомоза, жизнеспособность киики, флуоресиенция, НАДН

Для цитирования: Захаренко А. А., Беляев М. А., Трушин А. А., Зайцев Д. А., Курсенко Р. В. Сидоров В. В. Юкина Г.Ю. Сухорукова Е. Г., Свечкова А. А. Комбинированная оценка жизнеспособности киики методами лазерной допплеровской флоуметрии и лазерной флуоресцентной спектроскопии. Регионарное кровообращение и микрочиркуляция. 2021;20(2):70-76. Doi: 10.24884/1682-6655-2021-20-2-70-76.

UDC $616.34,616-005.4$

DOI: 10.24884/1682-6655-2021-20-2-70-76

A. A. ZACHARENKO' ${ }^{1}$, M. A. BELYAEV ${ }^{1}$, A. A. TRUSHIN ${ }^{1}$, D. A. ZAYTCEV ${ }^{1}$, R. V. KURSENKO' ${ }^{1}$ V. V. SIDOROV ${ }^{2}$, G. Y. YUKINA' ${ }^{1}$, E. G. SUKHORUKOVA' ${ }^{1}$ A. A. SVECHKOVA ${ }^{1}$

\section{Combined assessment of intestinal viability using laser doppler flowmetry and laser fluorescence spectroscopy}

1 Pavlov University, Saint Petersburg, Russia

6-8, L'va Tolstogo str., Saint Petersburg, Russia, 197022

${ }^{2}$ LLC SPE «LAZMA», Moscow, Russia

8, Tvardovskogo str., Moscow, Russia, 123458

E-mail:9516183@mail.ru

Received 17.11.20; accepted 05.02.21

\section{Summary}

Introduction. The development of an objective non-invasive method for intraoperative assessment of intestinal viability remains urgent for modern surgery. In this context, the method of laser fluorescence spectroscopy (LFS) of coenzymes of oxidative metabolism, as well as a combination of this technique with the simultaneous use of laser Doppler flowmetry (LDF) seems 
promising. Materials and methods. The model of ischemia-reperfusion of the small intestine of 4 Californian Rabbits was used to study the relationship of the parameters of LFS and LDF with the histological picture. A model of intraoperative ischemia was used by temporarily clamping the trunk of the cranial mesenteric vascular bundle for $90 \mathrm{~min}$, followed by intraoperative and postoperative reperfusion for 60 minutes and 24 hours, respectively. LDF and LFS data were recorded from intestine at the end of the intraoperative reperfusion period. 24 hours after the surgery, the animals were subjected to histologic evaluation of intestine ischemic changes, which were compared with the LDF and LFS data. Diagnostic value of LDF and LFS, and their combination for intraoperative assessment of intestinal viability were analyzed. Results. A significant correlation was found between the parameters of LDF, LFS and the degree of ischemic changes according to the histological data. The method of isolated assessment of the difference in the fluorescence of reduced nicotin adenine dinucleotide (NADH) before and after ischemia-reperfusion $(77.3 \%)$ has the greatest diagnostic value. The method has the highest sensitivity with a combination of differences in LDF and LFS values before and after ischemia-reperfusion $(85.7 \%)(\mathrm{P}<0.05)$. Conclusions. LFS, as well as its combination with LDF, is a useful method for objective assessment of intestinal viability, which requires further research and has potential for clinical use.

Keywords: microcirculation, anastomotic leakage, intestinal viability, fluorescence, NADH

For citation: Zacharenko A. A., Belyaev M. A., Trushin A. A., Zaytcev D. A., Kursenko R. V., Sidorov V. V., Yukina G. Y., Sukhorukova E. G., Svechkova A. A. Combined assessment of intestinal viability using laser doppler flowmetry and laser fluorescence spectroscopy. Regional hemodynamics and microcirculation. 2021;20(2):70-76. Doi: 10.24884/1682-6655-2021-20-2-70-76.

\section{Введение}

Интраоперационная оценка жизнеспособности кишечной стенки остается нерешенной проблемой современной хирургии. Примерами применяемых в клинической практике способов являются флюоресцентная ангиография с индоцианином зеленым, лазерная допплеровская флоуметрия (ЛДФ). Стоит отметить, что данные способы оценки жизнеспособности ткани основаны на изолированной оценке регионарного кровотока.

В контексте оценки жизнеспособности кишечной стенки малоизученным, но перспективным для внедрения в клиническую практику представляется способ лазерной флуоресцентной спектроскопии (ЛФС) кофермента окислительного метаболизма - восстановленной формы никотинадениндинуклеотида (НАДН), являющегося эндогенным флуорофором, участвующим в переносе энергии на дыхательную цепь клетки в виде электронов от клеточных субстратов (белки, жиры, углеводы) при участии кислорода [1].

В условиях гипо- и аноксии происходит замедление утилизации данного кофермента, что и определяет корреляцию интенсивности флуоресценции в зависимости от адекватности доставки кислорода тканям [2].

При оценке жизнеспособности ткани перспективным является способ комбинированной одновременной оценки микроциркуляции методом ЛДФ и окислительного метаболизма способом ЛФС $[1,2]$.

Данный комбинированный способ оценки жизнеспособности ткани является недостаточно исследованным и представляется перспективным в рамках применения при интраоперационной объективной оценке жизнеспособности кишечной стенки.

С целью оценки достоверности и перспективности комбинированного способа оценки жизнеспособности кишечной стенки методами ЛДФ и ЛФС нами выполнено исследование по анализу показателей ЛДФ и ЛФС и гистопатологических изменений в участке кишки кролика в условиях его ишемического и реперфузионного повреждения.

\section{Материалы и методы исследования}

Исследование выполнено на 4 лабораторных животных породы «Кролик Калифорнийский». Эксперименты были одобрены Этическим комитетом ПСПбГМУ им. И. П. Павлова (протокол № 29/19 от
25.11.2019 г.). Животные имели свободный доступ к корму и воде и содержались в условиях 12-часового светового дня.

Все кролики находились в условиях пищевой депривации в течение 12 ч до эксперимента. Введение и поддержание наркоза у всех животных обеспечивалось внутривенным введением в правую ушную вену раствора фентанила, с последующей эндотрахеальной интубацией и ИВЛ с параллельной продленной инфузией раствора натрия хлорида 0,9\%-го в объеме 10 мл/кг в час в течение всего времени оперативного вмешательства. После выполнения срединной лапаротомии был выделен периферический сегмент краниального брыжеечного сосудисто-нервного пучка, кровоснабжающего терминальный участок подвздошной кишки, длиной 45 см, при этом каждые 5 см выделенного участка помечались серозно-мышечным швом (рис. 1). Впоследствии краниальные брыжеечные артерия и вена пережимались сосудистой клипсой. Дополнительно производилось лигирование пристеночных брыжеечных сосудов, питающих центральные 25 см исследуемого участка подвздошной кишки,

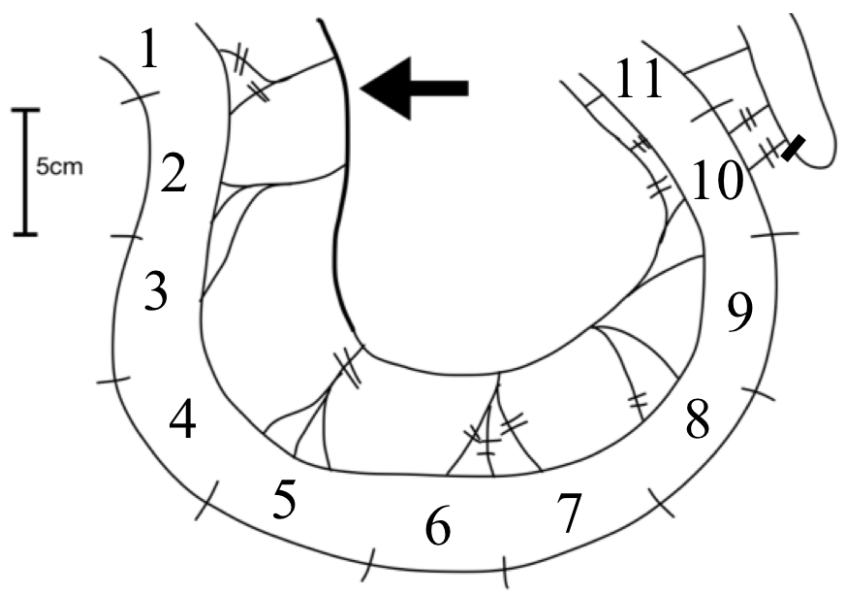

Рис. 1. Схема экспериментальной модели. Стрелка указывает на место пережатия пучка краниальных брыжеейчных сосудов. Двойные линии показывают места лигирования прямых сосудов брыжеечного края кишки. Участки от 1 до 10 пронумерованы в зависимости от эпицентра ишемии. Участки 1 и 11 - вне зоны ишемии

Fig. 1. Experiment scheme. Arrow shows the level of cranial mesenteric vessels occlusion. Ligated vasa recta of bowel mesenteric margin are duble-lined. Segments of bowel are marked from 1 to 11 according to ischemia area. Segments 1 and 11 are outside of ischemia area 
а также лигирование краевых ответвлений краниальных артерии и вены по границам исследуемого 45-сантиметрового сегмента подвздошной кишки. После 90 мин ишемии клипса с краниального сосудистого пучка снималась, и затем производилась реперфузия терминального отдела подвздошной кишки в течение 60 мин. Измерения уровня микроциркуляции крови и амплитуды флуоресценции коферментов окислительного метаболизма производились на лазерном анализаторе периферического кровотока, лимфотока и коферментов ткани «ЛАЗМА-Д» (рег.уд. № РЗН 2017/5844 от 8.06.2017 г.).

Согласно протоколу исследования, регистрация параметров осуществлялась посредством контакта оптического волоконного зонда аппарата с серозной поверхностью подвздошной кишки.

После стабилизации выводимого в интерфейсе программного обеспечения графика аутофлуоресценции и уровня перфузии производилась регистрация амплитуды флуоресценции $\mathrm{A}_{\text {надн }}$, измеряемой в относительных единицах (о. е.), на длине волны 460 нм, нормированной на амплитуду интенсивности обратно отраженного возбуждаемого флуоресценцию излучения на длине волны 365 нм. Длительность регистрации составляла 30 с. В течение регистрации аутофлуоресценции происходила параллельная регистрация значений показателя микроциркуляции, измеряемых в перфузионных единицах (п. е.), в течение $30 \mathrm{c}$.

Регистрация показателей производилась в 11 сегментах по 5 см. Из них 2 сегмента с неизмененной перфузией были расположены до и после отрезка с выключенным мезентериальным кровотоком, в то время как 9 других сегментов, расположенных в зоне выключенного мезентериального кровотока, подвергались ишемии. Запись показателей ЛДФ и ЛФС производилась до выключения периферического кровотока, через 90 мин ишемии и через 60 мин реперфузии, после чего ушивалась лапаротомная рана и кролик выводился из наркоза. Известно, что длительное пережатие краниальных брыжеечных сосудов кролика и их реперфузия во время операции вызывают гибель животного раньше формирования необратимых ишемических изменений в стенке кишки [6]. Таким образом, выведение животного и гистологическое исследование подвергнутого ишемии и реперфузии сегмента подвздошной кишки производилось спустя 24 ч послеоперационного периода.

Выполнено микроскопическое исследование гистологических препаратов, окрашенных гематоксилин-эозином, изготовленных из помеченных ранее серозно-мышечными швами сегментов по 5 см исследуемого ишемизированного терминального отдела подвздошной кишки. Гистопатологические ишемические изменения оценивали по 6 степеням: степень 0 - нет ишемических изменений стенки кишки; степень 1 - легкий или умеренный отек в пределах слизистой оболочки; степень 2 - подслизистый отек без признаков изъязвлений; 3 - подслизистый отек и (или) изъявления слизистой; степень 4 - подслизистые кровоизлияния; степень 5 - трансмуральный некроз стенки кишки. Изменения 0-3-й степеней рассматривались как обратимые и соответствующие жизнеспособной стенке кишки, в то время как ишемические изменения 4-5-й степени соответствовали нежизнеспособному участку кишки [1].

Проведен анализ репрезентативности и равномерности значений показателей ЛДФ и НАДНфлуоресценции, зафиксированных до ишемии исследуемого терминального отдела подвздошной кишки. Проведен сравнительный анализ зафиксированных значений показателей ЛДФ и НАДН-флуоресценции на 60-й минуте реперфузии с результатами гистологического исследования кишечной стенки с определением их корреляции.

Также проведен сравнительный анализ разниц значений показателей ЛДФ и НАДН-флуоресценции до и после ишемии-реперфузии с результатами гистологического исследования с определением их корреляции.

Проведен анализ комбинированной оценки жизнеспособности кишечной стенки по одновременному учету показателей ЛДФ и НАДН-флуоресценции в определенном участке кишки.

Статистический анализ. Оценка равномерности полученных значений ЛДФ и НАДН-флуоресценции проведена с использованием критерия Колмогорова - Смрнова. Статистическая значимость отличий значений ЛДФ и НАДН-флуоресценции на разных участках ишемии кишки оценивалась по критерию Вилкоксона. Выполнена оценка чувствительности, специфичности и точности методики по выявлению нежизнеспособных участков кишки.

Статистический анализ проводили с использованием программы «Microsoft Office Excel».

\section{Результаты исследования и их обсужление}

Средние значения показателя микроциркуляции и амплитуды флуоресценции кофермента окислительного метаболизма НАДН по данным ЛДФ и ЛФС в 44 измерениях до ограничения мезентериального кровотока составили: $\mathrm{M}_{\text {пм }}=29,1$ п. е. и $\mathrm{A}_{\text {надн }}=0,82$ о. е. Распределения значений показателей ЛДФ и НАДНфлуоресценции были репрезентативными и равномерными при оценке по критерию Колмогорова Смирнова $(\mathrm{p}=0,722 ; \mathrm{p}=0,519)$.

Гистологическая картина исследованных участков кишки приведена на рис. 2. Степень ишемических изменений стенки кишки соответствовала удаленности от центра ишемии, при этом необратимые ишемические изменения (4-5-й степени) отмечались в центральных отделах сегмента кишки.

При сравнительном анализе выявлена корреляция показаний прибора и гистологической картины. Пороговые значения микроциркуляции и амплитуды флуоресценции НАДН, соответствующие 0-3-й степеням ишемических изменений, составили $\mathrm{M}_{\text {пм }}>21,81$ п. е., $\mathrm{A}_{\text {надн }}<0,985$ о. е. (рис. 3).

Чувствительность, специфичность и точность регистрации некроза (патогистологических изменений 4-5-й степени) в стенке кишки после эпизода ишемии-реперфузии составили для ЛДФ 78,3, $65,1,69,7 \%$; для НАДН-флуоресценции - 78,3, $62,8,68,2 \%$. 
ОРИГИНААЬНЫЕ СТАТЬИ (экспериментальные исслеАования) / ORIGINAL ARTICLES (experimental investigations)

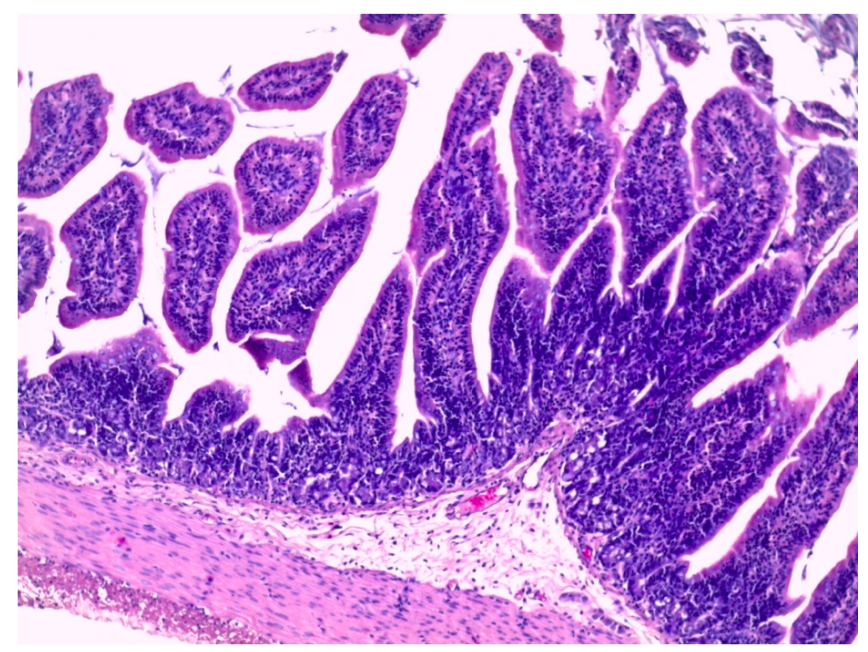

Стадия 1 - легкий/умеренный отек слизистой оболочки

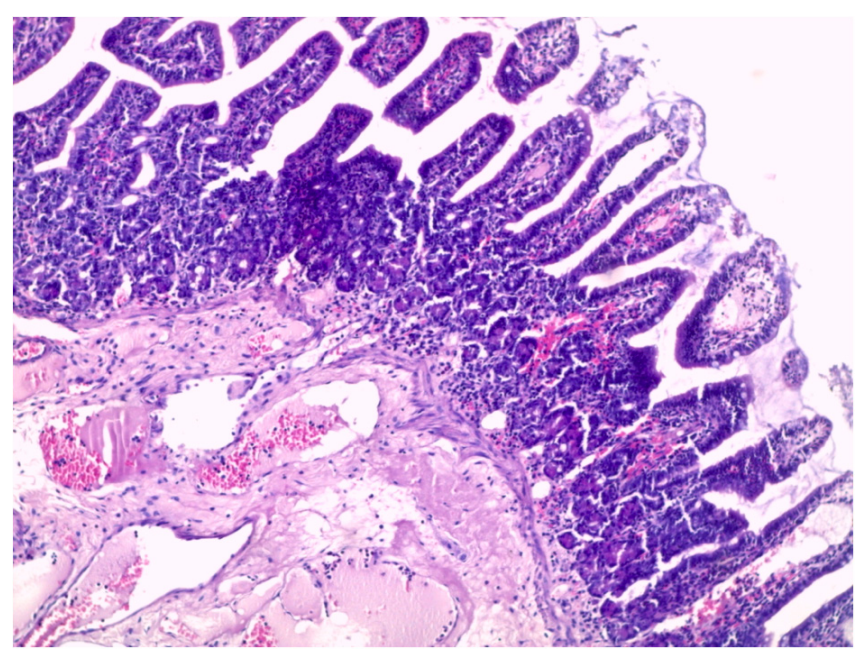

Стадия 3 - отек подслизистой оболочки и/или полнокровие (венозный застой) - с изъязвлениями

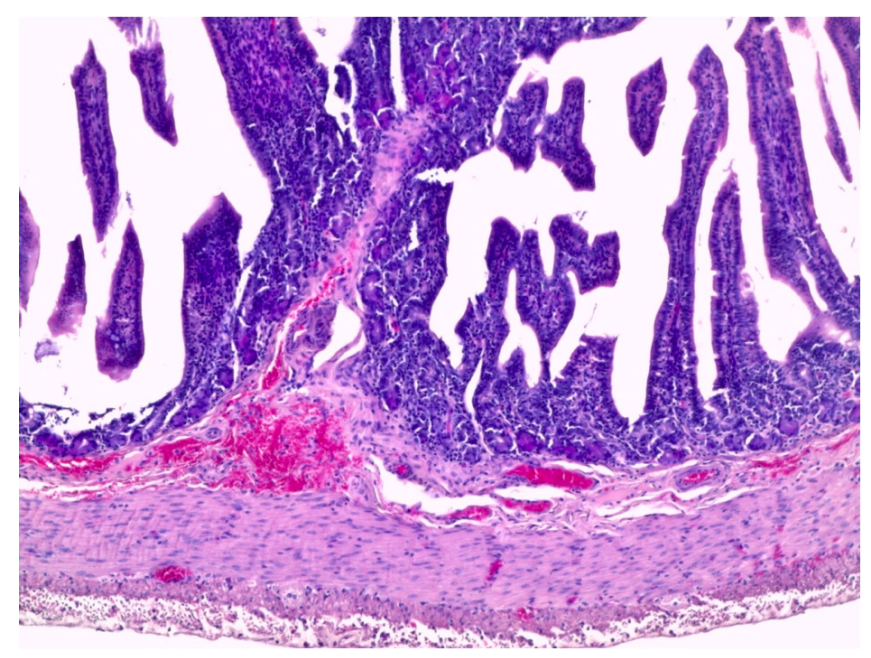

Стадия 2 - отек подслизистой оболочки и/или полнокровие (венозный застой) - без изъязвлений

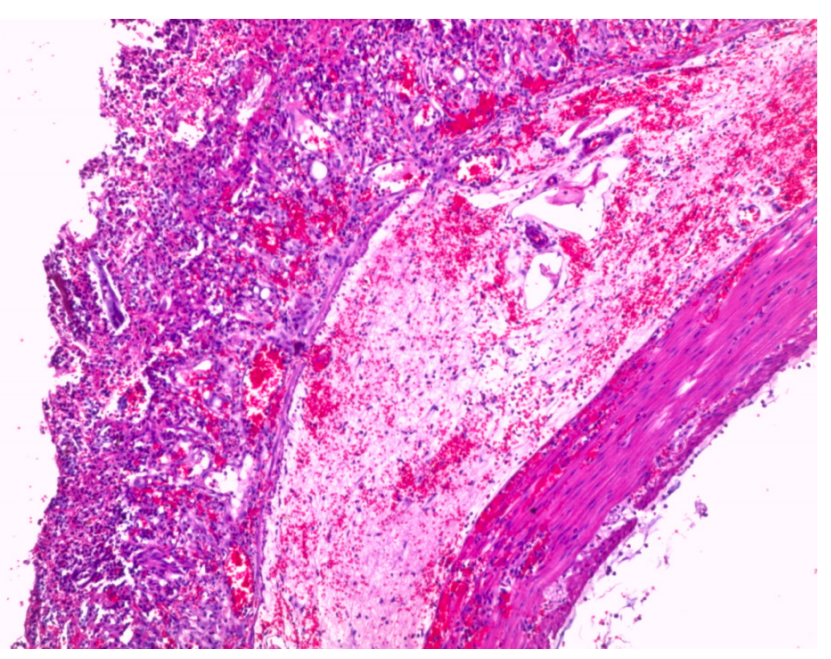

Стадия 4 - подслизистые кровоизлияния

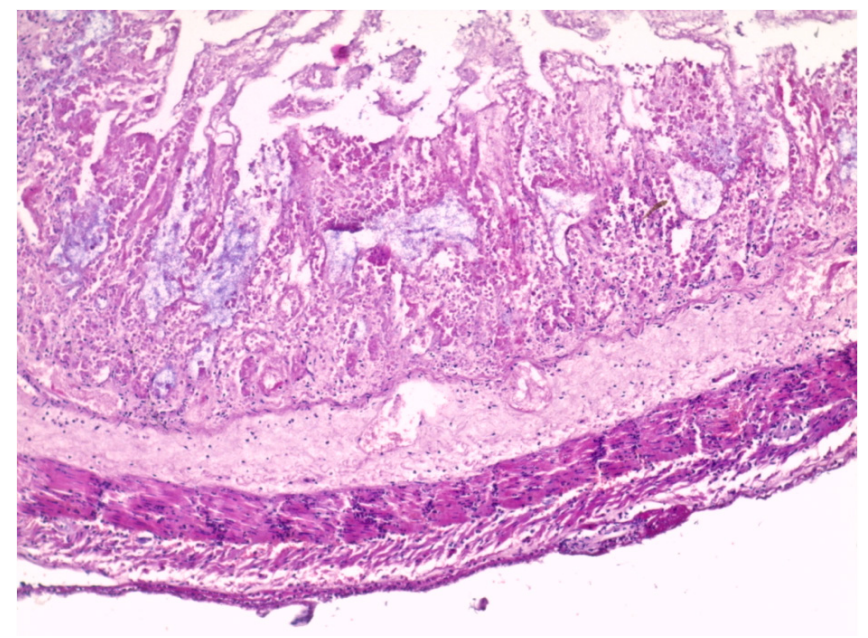

Стадия 5 - трансмуральный некроз

Рис. 2. Полученные патогистологические изменения в стенке кишки в зависимости от удаленности от эпицентра ишемии

Fig. 2. Pathomorphologic changes in bowel according to distance from ischemia-reperfusion area 

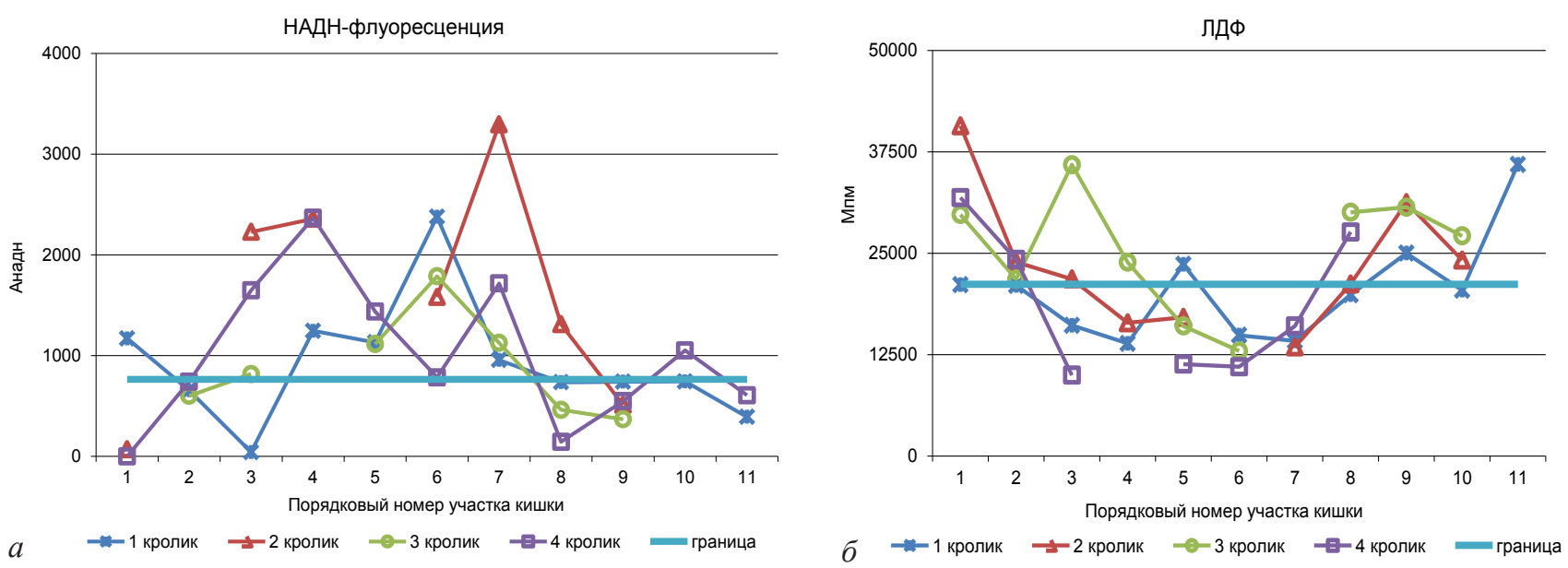

Рис. 3. Разброс значения А в вависимости от удаленности от эпицентра ишемии (a); разброс значений ПМ регистрированных с помощью ЛДФ в зависимости от эпицентра ишемии (б): * - пороговые значения амплитуды флуоресценции НАДН для жизнеспособной кишки $\mathrm{A}_{\text {надн }}<0,985$ о. е.; ** - пороговые значения микроциркуляции для жизнеспособной кишки $\mathrm{M}_{\text {пм }}>21,81$ п. е.

Fig. 3. NADH-autofluorescence parametres in bowel according to distance from ischemic-reperfusion area $(a)$; microcirculation parametres by LDF in bowel according to distance from ischemic-reperfusion area (б): * - threshold values of the amplitude of NADH fluorescence for viable intestine $A_{\text {nadh }}<0,985$ relative units (r. u.); ** - threshold values of microcirculation for viable intestine $\mathrm{M}_{\mathrm{pm}}>21.81$ p. u.

При комбинации обоих параметров чувствительность, специфичность и точность регистрации некроза составили $82,6,65,1,71,2 \%$.

Чувствительность, специфичность и точность регистрации некроза при анализе разниц значений показателей ЛДФ и НАДН-флуоресценции до и после ишемии-реперфузии (АЛДФ и $\Delta$ НАДН-флуоресценция) составили $85,7,53,3$, 63,6 \% для ЛДФ; 78,6, 76,7, 77,3 \% - для НАДНфлуоресценции.

При комбинации обоих показателей разниц значений ЛДФ и НАДН-флуоресценции до и после ишемии-реперфузии (АЛДФ+АНАДН-флуоресценция) чувствительность, специфичность и точность регистрации некроза - составили $85,7,66,7,72,7$ \%. Полученные параметры диагностических значимостей методик резюмированы в табл. 2 .

Интраоперационная оценка жизнеспособности кишки на сегодняшний день, в большинстве своем, осуществляется субъективно - по окраске, пульсации брыжеечных сосудов, перистальтике и является недостаточно надежной [1].

ЛДФ является одной из активно применяемых методик объективной оценки жизнеспособности стенки кишки [1]. В экспериментальных исследованиях показана тесная корреляция показателей ЛДФ и степени ишемических изменений по данным гистологического исследования [1].

По данным литературы [1] интраоперационное применение ЛДФ позволяет выявить критическое снижение кровоснабжения стенки кишки, в частности, в зоне анастомоза, и снизить число несостоятельностей при соответствующей коррекции оперативного приема.

Метод ЛДФ, как и многие другие способы оценки жизнеспособности стенки кишки по уровню регионарного кровотока, не учитывает локальную гетерогенность микроциркуляции $[1,2]$.

К тому же в условиях длительной ишемии и последующей реперфузии признаки адекватного регионарного кровотока могут замаскировать произошед- шие реперфузионные повреждения и необратимые морфологические изменения в тканях.

В нашей работе мы исследовали диагностическую ценность не связанного с оценкой регионарного кровотока способа: метода регистрации амплитуды флуоресценции кофермента окислительного метаболизма - НАДН. Также исследован потенциал комбинированного применения ЛДФ и ЛФС в оценке жизнеспособности кишечной стенки в эксперименте.

В нашем эксперименте мы использовали модель с пережатием мезентериального кровотока на 90 мин и исследованием гистологического материала спустя 24 ч послеоперационного периода в условиях реперфузии исследуемого участка кишки. Данная модель выбрана нами ввиду того, что время технически возможного интраоперационного пережатия мезентериального кровотока у кролика недостаточно для достижения морфологически определяемого некроза кишечной стенки к концу операции. Более длительное пережатие краниальных брыжеечных сосудов вызывает гибель животного раньше формирования необратимых ишемических изменений в стенке кишки. Выбранная нами модель позволила получить необратимые ишемические изменения в стенке кишки кролика и сравнить их с интраоперационными инструментальными данными.

Выявлена статистическая репрезентативность измерения обоих показателей (уровня микроциркуляции по данным ЛДФ и уровня окислительного метаболизма по данным НАДН-флуоресценции).

В исследовании M. Ando et al. [7] показана корреляция параметров бесконтактной ЛДФ и степени ишемических патогистологических изменений. Чувствительность, специфичность и диагностическая ценность метода при этом составили $88,63,76 \%$ соответственно.

Изолированная оценка жизнеспособности кишки по уровню НАДН-флуоресценции оказалась сопоставимой по чувствительности, но несколько ниже по специфичности, чем контактная ЛДФ.

При комбинации обоих параметров - контактной ЛДФ и НАДН -флуоресценции - отмечено повыше- 
ОРИГИНААЬНЫЕ СТАТЬИ (экспериментальные исслеАования) / ORIGINAL ARTICLES (experimental investigations)

Таблица 1

Степени гистологических изменений (0-5) в зависимости от участка ишемии кишки

Table 1

Histological grade (0-5) according to ischemic area

\begin{tabular}{l|c|c|c|c|c|c|c|c|c|c|c|}
\hline \multicolumn{1}{c|}{ Кролик } & Точка 1 & Точка 2 & Точка 3 & Точка 4 & Точка 5 & Точка 6 & Точка 7 & Точка 8 & Точка 9 & Точка 10 & Точка 11 \\
\hline 1 & 2 & 2 & 4 & 4 & 4 & 5 & 5 & 2 & 2 & 2 & 1 \\
\hline 2 & 2 & 5 & 5 & 5 & 5 & 5 & 5 & 2 & 2 & 1 & 1 \\
\hline 3 & 2 & 3 & 3 & 5 & 5 & 4 & 3 & 3 & 2 & 2 & 2 \\
\hline 4 & 2 & 2 & 3 & 3 & 3 & 3 & 3 & 3 & 3 & 2 & 1
\end{tabular}

Таблица 2

Чувствительность, специфичность и точность определения параметров ЛДФ и НАДН-флуоресценции при регистрации некроза участка кишки, \%

Table 2

Sensitivity, specificity and accuracy of LDF and NADH-fluorescence for recording necrotic intestine, \%

\begin{tabular}{|c|c|c|c|}
\hline \multirow{2}{*}{ Параметр } & \multicolumn{3}{|c|}{ Метод } \\
\hline & чувствительность & специфичность & точность \\
\hline ЛДФ после ишемии-реперфузии & 78,3 & 65,1 & 69,7 \\
\hline НАДН-флуоресценция после ишемии-реперфузии & 78,3 & 62,8 & 68,2 \\
\hline ЛДФ + НАДН-флуоресценция после ишемии-реперфузии & 82,6 & 65,1 & 71,2 \\
\hline АЛДФ («до» - «после» ишемии-реперфузии) & 85,7 & 53,3 & 63,6 \\
\hline АНАДН-флуоресценция & 78,6 & 76,7 & 77,3 \\
\hline$\Delta$ ЛДФ+АНАДН-флуоресценция & 85,7 & 66,7 & 72,7 \\
\hline
\end{tabular}

ние чувствительности, специфичности и диагностической ценности метода.

Принимая во внимание возможность флуоресценции других структурных элементов ткани, например, коллагена, являющимся более константным компонентом по сравнению с динамически изменяющейся концентрацией НАДН, нельзя исключить вклад оптических помех от этих константных флуорофоров в получаемые значения [1].

С целью исключения вклада оптических помех, а также возможной индивидуальной изменчивости показателей ЛДФ и ЛФС в здоровой стенке кишки мы провели статистический анализ и корреляцию со степенью патогистологических ишемических изменений значений разниц уровня микроциркуляции и НАДН-флуоресценции до и после ишемии-реперфузии в одних и тех же исследуемых участках кишки.

При анализе оценки жизнеспособности стенки кишки до и после ишемии-реперфузии отмечено значимое повышение диагностической ценности обоих показателей изолированно. При этом более высокая чувствительность - у методики контактной ЛДФ $(85,7$ \%). Чувствительность методики при оценке уровня НАДН-флуоресценции осталась на прежнем уровне, однако специфичность метода оказалась более высокой, что обусловило и бо́льшую диагностическую ценность (77,3\%).

При комбинации обеих методик при анализе оценки жизнеспособности стенки кишки до и после ишемии-реперфузии отмечен высокий показатель чувствительности, равный изолированной оценке по разнице значений ЛДФ, однако повысились специфичность и диагностическая ценность методики.

Таким образом, комбинация результатов оценки жизнеспособности стенки кишки повышает чувствительность методики по выявлению участков с необратимыми ишемическими изменениями. При этом повышение диагностической ценности методики возможно за счет оценки разницы значений показателей ЛДФ и НАДН-флуоресценции до и после ишемии-реперфузии за счет нивелирования вклада оптических помех от константных флуоресцирующих компонентов тканей и состояния системной гемодинамики.

\section{Заключение}

Методика измерения уровня флуоресценции кофермента окислительного метаболизма - НАДН представляется перспективной для интраоперационной оценки жизнеспособности кишечной стенки. Оценка жизнеспособности стенки кишки по уровню разницы НАДН-флуоресценции обладает бо́льшей диагностической ценностью и определяет потенциал данной методики для дальнейших исследований и последующего практического применения. Более высокая чувствительность комбинированной оценки жизнеспособности кишки по состоянию микроциркуляции и активности окислительного метаболизма доказывает целесообразность комбинированного подхода в диагностике. 


\section{Конфмикт интересов / Conflict of interest}

Авторы заявили об отсутствии конфликта интересов. / The authors declare no conflict of interest.

\section{Аитература / References}

1. Власов Т. Д., Корнюшин О. В., Папаян Г. В. Возможности аутофлуоресиентной органоскопии при ишемическом и реперфузионном повреждении тонкой киики in vitro // Регионарноекровообращение имикрочиркулящия. -2009. -№ 2. -C. 73-75. [Vlasov TD, Kornjushin OV, Papajan GV.Autofluorescent organoscopy as a tool for detection of early ischemia-reperfusion injury of the small intestine in vitro. Regional blood circulation and microcirculation. 2009;(2):73-75. (In Russ.)].

2. Шинкин М. В., Звенигородская Л. А., Мкртумян А. М. Лазерная допплеровская флоуметрия и флуоресцентная спектроскопия как методы оченки доклинических проявлений синдрома диабетической стопы // Эффективная фармакотерапия. - 2018. № 18. - C. 20-26. [Shinkin MV, Zvenigorodskaya LA, Mkrtumyan AM. Lazer Doppler Flowmetry and Fluorescence Spectroscopy as Methods for Preclinical Manifestations of Diabetic Foot Syndrome Assessment. Effektivnaya farmakoterapiya. 2018; (18):20-26. (In Russ.)].

3. Захаренко А. А., Беляев М. А., Трушин А. А. и др. Интраопераџионная оценка жизнеспособности стенки кишки (обзор литературы) // Вестн. хир. им. И. И. Грекова. - 2020. - T. 22, № 1. - C. 82-88. [Zacharenko AA, Belyaev MA, Trushin AA, Zaytcev DA, Kursenko RV. Bowel viability assessment during surgery (review of the literature) // Grekov's Bulletin of Surgery. 2020;179(1):82-88. (In Russ.)]. Doi: 10.24884/0042-4625-2020-179-1-82-88.].

4. Chiu CJ, McArdle AH, Brown R, Scott HJ, Gurd FN. Intestinal mucosal lesion in low-flow states. Arch Surg. 1970;101(4):478483. Doi: 10.1001/archsurg.1970.013402 80030009.

5. Urbinavicus L, Pattyn P, de Putte DV, Venskutoris D. How to assess intestinal viability during surgery: a review of technques. World J Gastrointestinal Surg. 2011;3(5):59-69. Doi: 10.4240/wjgs.v3.i5.59.

6. Rajan V, Varghese B, Van Leeuwen TG, Steenbergen W. Review of methodological developments in laser Doppler flowmetry. Lasers Med. Sci. 2009;(24):269-283. Doi: 10.1007/ s10103-007-0524-0.

7. Ando M, Ito M, Nihei Z, Sugihara K. Assessment of intestinal viablity using a non-contact laser tissue blood flowmeter. Am J Surg. 2000;180(3):176-180. Doi: 10.1016/s00029610(00)00444-x.

8. Vignali A, Gianotti L, Braga M. Radaelli G, Malvezzi L. Altered microperfusion at the rectal stump is predictive for rectal anastomotic leak. Dis. Colon Rectum. 2000;43(1):76-82. Doi: 10.1007/BF02237248.

9. Seike K, Koda K, Saito N, Oda K, Kosugi C, Shimizu K, Miyazaki M. Laser Doppler assessment of the in uence of division at the root of the inferior mesenteric artery on anastomotic blood flow in rectosigmoid cancer surgery. Int J Colorectal Dis. 2007;22(1):689-697. Doi: 10.1007/s00384-006-0221-7.

10. Hirano Y, Omura K, Tatsuzawa Y, Shimizu J, Kawaura Y, Watanabe G. Tissue oxygen saturation during colorectal surgery measured by near-infrared spectroscopy: pilot study to predict anastomotic complications. World J Surg. 2006: 30(3):457-461. Doi: 10.1007/s00268-005-0271-y.

11. Сидоров В. В., Рыбаков Ю. А., Гукасов В.М. Диагностический подход для оченки состояния микрочикуляторно-тканевой системы с использованием лазерных технологий и температурной фукциональной пробы // Инноватика и экспертиза. - 2018. - Т. 22, № 1. - С. 135 141. [Sidorov VV, Rybakov YUA, Gukasov VM. Diagnostic approach for estimation of the state of microcirculator-tissue system using laser technologies and temperature functional sample. Innovatics and Expert Examination. 2018;22(1):135141. (In Russ.)].

\section{Информация об авторах}

Захаренко Алексаньр Анатольевич - - -р мед. наук, руководитель отАела онкохирургии, НИИ хирургии и неотложной медицины, ПСПбГМУ им. И. П. Пав^ова, Санкт-Петербург, Россия, e-mail: 9516183@mail.ru.

Беляев Михаил Алексеевич - канд. меА. наук, руководитель онкологического отАеления № 1, НИИ хирургии и неотложной медицины, ПСПбГМУ им. И. П. Пав^ова, СанктПетербург, Россия, е -mail: 8628926@mail.ru.

Трушин Антон Александрович - зав. онкологическим отАелением № 1, НИИ хирургии и неотложной медицины, ПСПбГМУ им. И. П. Пав^ова, Санкт-Петербург, Россия, e-mail: anton.trushin@rambler.ru.

Зайцев $\Delta$ анима Александрович - врач-хирург хирургического отАеления № 4, НИИ хирургии и неотложной медицины, ПСПбГМУ им. И. П. Пав^ова, Санкт-Петербург, Россия, е -mail: zaytsev.danila@gmail.com.

Курсенко Роман Вацимович - врач-хирург хирургического отАеления № 1, НИИ хирургии и неотложной медицины, ПСПбГМУ им. И. П. Пав^ова, Санкт-Петербург, Россия, е -mail: romakurss@gmail.com.

Сицоров Виктор Васимьевич - генеральный директор, ООО «НПП "ААЗМА"», Москва, Россия, e-mail: victor.v.sidorov@ gmail.com.

Юкина Галина Юрьевна - канд. биол. наук, зав. лабораторией патоморфологии Научно-исследовательского центра, ПСПбГМУ им. И. П. Пав^ова, Санкт-Петербург, Россия, e-mail: pipson@inbox.ru.

Сухорукова Елена Геннадьевна - кань. мед. наук, старший научный сотрудник лаборатории патоморфологии Научноисследовательского центра, ПСПбГМУ им. И. П. Павлова, Санкт-Петербург, Россия, e-mail: len48@inbox.ru.

Свечкова Анна Алексеевна - врач-ординатор кафедры хирургии фракультетской с курсами ^апароскопической и серцечно-сосудистой хирургии с кАиникой, ПСПбГМУ им. И. П. Павлова, Санкт-Петербург, Россия, e-mail: svechkova-95@mail.ru.

\section{Authors information}

Zaharenko Aleksandr A. - Dr. of Sci. (Med.), Division Chair, Research Institute of Surgery and Emergency Medicine, Pavlov University, Saint Petersburg, Russia, e-mail: 9516183@mail.ru.

Belyaev Mihail A. - Cand. of Sci. (Med.), Department Head of Abdominal Oncology Department, Research Institute of Surgery and Emergency Medicine, Pavlov University, Saint Petersburg, Russia, e-mail: 8628926@mail.ru.

Trushin Anton A. - Abdominal Oncology Department Head, Research Institute of Surgery and Emergency Medicine, Pavlov University, Saint Petersburg, Russia, e-mail: anton.trushin@rambler.ru.

Zajcev Danila A. - Surgeon, Emergency surgery department, Research Institute of Surgery and Emergency Medicine, Pavlov University, Saint Petersburg, Russia, e-mail: zaytsev.danila@gmail.com.

Kursenko Roman V. - Surgeon, Abdominal Oncology Department, Research Institute of Surgery and Emergency Medicine, Pavlov University, Saint Petersburg, Russia, E-mail: romakurss@ gmail.com.

Sidorov Victor V. - General Director, LLC «SPE "LAZMA"», Moscow, Russia, e-mail: victor.v.sidorov@gmail.com.

Yukina Galina Yu. - Cand. of Sci. (Biol.), Head of the Laboratory of Pathomorphology of the Research Center, Pavlov University, Sain Petersburg, Russia, e-mail: pipson@inbox.ru.

Sukhorukova Elena. G. - Cand. of Sci. (Med.), Senior Researcher of the Laboratory of Pathomorphology of the Research Center, Pavlov University, Saint Petersburg, Russia, e-mail: len48@inbox.ru.

Svechkova Anna A. - Resident Doctor, Department of Faculty Surgery with Courses of Laparoscopic and Cardio-vascular Surgery with Clinic, Pavlov University, Saint Petersburg, Russia, e-mail: svechkova-95@mail.ru. 